\title{
Editorial: Boas novas em Texto Poético
}

Neste primeiro semestre de 2011, em que publicamos o número 10 da revista eletrônica TextoPoético (órgão oficial do GT Teoria do Texto Poético, da ANPOLL, cujo site é www.textopoetico.com.br), queremos chamar a atenção para outras novidades importantes: além das entrevistas com poetas, iniciadas em 2010, este ano também passamos a publicar resenhas de livros de poesia e/ou de teoria e crítica de poesia lançados recentemente, no Brasil e/ou no exterior. Além disso, é com orgulho que informamos que a TextoPoético está indexada, para consulta permanente dos interessados, em duas bases internacionais de periódicos, sendo uma brasileira (http://portalnuclear.cnen.gov.br/livre/ConsultaPorLetra.asp?Letra=T) e outra mexicana (http://latindex.unam.mx/buscador/ficRev.html?folio=20276amp;opcion=1).

Em termos poético-acadêmicos, cabe ressaltar que o presente volume abre-se com uma entrevista com o poeta Paulo Franchetti (mais conhecido como professor da UNICAMP), bela e sutilmente conduzida pela vice-coordenadora do GT, Profa. Dra. Solange Fiuza Cardoso Yokozawa (UFG/Goiânia).

A seção a seguir apresenta oito artigos sobre temas variados da literatura universal, sendo que os três primeiros enfocam o século XIX e a consolidação da modernidade em várias literaturas. O de Celina Maria Moreira de Mello (UFRJ), "O poeta na cena moderna", trata da literatura francesa e dos vários modos como nesta, pelos anos 1830-1840, a literatura se une à pintura e à gravura para oferecer tanto relatos pictóricos pinçados de cartas e comunicações ligeiras, quanto alguns "quadros parisienses" narrativos, anteriores aos de Baudelaire. Já o estudo de Otávio Guimarães Tavares (UFSC), "Um corpo sem fim: a obra de Walt Whitman como corpo ilimitado, corpo em expansão, corpo fragmentário", aborda aspectos da obra do conhecido poeta, pai da modernidade lírica norte-americana. Por seu turno, o artigo "Modernidade e razão crítica em Cesário Verde", de Telma Borges (UNIMONTES), estuda em detalhes o mais conhecido poema do português Cesário Verde, "O sentimento dum ocidental”, e suas relações com a cidade moderna (Lisboa) e, claro, com a tradição camoniana. 
O quarto texto, "Confins poéticos: contemporaneidade e romantismo na poesia finlandesa", de Carolina Alves Magaldi (UFJF), faz a ponte entre o século XIX e o entre-séculos XX/XXI, ao atar a primeira obra poética da distante e pouco conhecida Finlândia - o épico romântico-nacional e "artificial” Kalevala (há pouco traduzido entre nós) - ao trabalho do jovem poeta contemporâneo Juhana Vähänen.

Os quatro artigos seguintes tratam da poesia brasileira, ainda de extração "modernista" (Maria de Fátima Gonçalves de Lima (PUC/GO), em "O discurso do poema $O$ rio como expressão do eu-lírico na poesia de João Cabral”, faz uma análise do percurso gerativo do famoso poema cabralino), ou já contemporânea: dos anos 70 a esta parte, o trabalho de Annita Costa Malufe (PUC/SP), "O não-senso em Ana Cristina Cesar e Marcos Siscar", procura o "não-dito" e o "não-sentido" na obra de ambos os poetas do título; os dois últimos estudos enfocam, de modo diverso, poesia e memória. Assim, enquanto o de Elaine Cristina Cintra (UFU), "Memória e melancolia em Estudos para o seu corpo de Fabrício Corsaletti", estuda a obra do jovem poeta paulista, o de Antonio Donizeti da Cruz (UNIOESTE), "Palavra poética e cartografias da memória em Arriete Vilela", ocupa-se da pouco conhecida poeta de Alagoas.

A seção de resenhas abre-se com a apresentação crítica de $A$ verdade da poesia (2007), de Michael Hamburger, por Wilson José Flores Jr. (UFRJ), e completa-se com sete recensões de livros de poesia publicados no Brasil entre 2008 e 2010: Um dia, o trem (2008), de Fernando Fábio Fiorese Furtado, é estudado por Maria Lúcia Outeiro Fernandes (UNESP/Araraquara); Entremilênios (2009), livro póstumo de Haroldo de Campos organizado por sua viúva Carmen de P. Arruda Campos, é resenhado por Susanna Busato (UNESP/São José do Rio Preto); A moeda do tempo e outros poemas (2009), antologia do português Gastão Cruz organizada por Jorge Fernandes da Silveira, é estudada por Ida Alves (UFF); o último Gullar, Em alguma parte alguma (2010), é resenhado por Alexandre de Melo Andrade (UNIESP/Ribeirão Preto), enquanto João Carlos Biella (UFU) se debruça sobre o último livro de Marcos Siscar, Interior via satélite (2010). A seção se encerra de modo circular, pois a última resenha, "Memória futura, poesia madura”, de Solange Fiuza Cardoso Yokozawa (UFG/Goiânia), ata-se à entrevista feita pela professora para a abertura deste $10^{\circ}$ volume da TextoPoético. Pois ela, agora, se ocupa não apenas com o livro publicado por Franchetti em 2010, Memória 
futura, mas termina por lançar luzes sobre as várias facetas da produção artísticoliterária do poeta de Matão.

Enfim, agradecemos aos queridos amigos do GT Teoria do Texto Poético (ANPOLL) e aos colegas profissionais das Letras (de várias latitudes e longitudes do Brasil) que nos ajudaram, com a emissão de pareceres circunstanciados, no processo de avaliação dos muitos artigos e resenhas recebidos para a revista, e esperamos que nossos habituais (e novos) leitores possam aproveitar ao máximo o rico conteúdo que temos a satisfação e a honra de tornar público. Boa leitura a todos!

Araraquara/Goiânia, dezembro de 2011

Prof. Dr. Antônio Donizeti Pires (UNESP/Araraquara)

Profa. Dra. Solange Fiuza Cardoso Yokozawa (UFG/Goiânia)

Coordenadores do GT Teoria do Texto Poético (ANPOLL) 